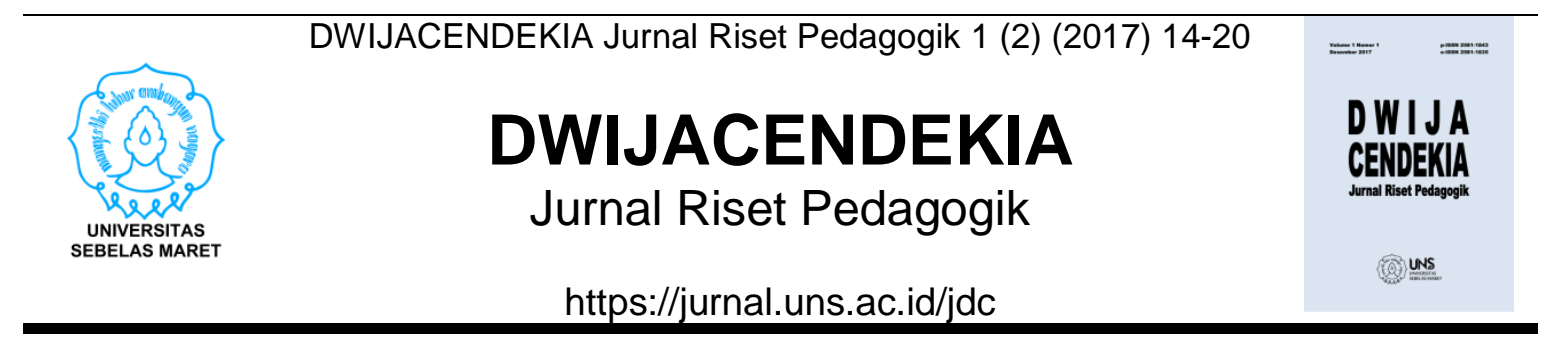

\title{
PENDIDIKAN KARAKTER PEDULI LINGKUNGAN DAN IMPLEMENTASINYA
}

\section{Dwi Purwanti}

SDN 1 Pohkumbang Karanganyar Kebumen

\section{Sejarah Artikel}

Diterima 15 September 2017

Disetujui 13 Oktober 2017

Diterbitkan 1 Desember 2017

\section{Kata Kunci}

pendidikan karakter, peduli lingkungan, implementasi

\begin{abstract}
Abstrak
Pola pendidikan sekolah bergerak dan berkembang sesuai dengan perkembangan ilmu pengetahuan teknologi yang tidak hanya mengajarkan aspek kognitif (pengetahuan) saja melainkan juga aspek afektif (sikap) dan aspek psikomotor (perilaku/kebiasaan). Berkaitan dengan sikap afektif, pemerintah telah menetapkan pendidikan karakter. Salah satu karakter yang dikembangkan adalah peduli lingkungan. Kajian ini difokuskan pada (1) konsep pendidikan karakter peduli lingkungan dan (2) implementasi pendidikan karakter peduli lingkungan di sekolah. Hasil kajian ini meliputi: (1) pendidikan karakter peduli lingkungan adalah perwujudan dari sikap manusia terhadap lingkungan berupa tindakan dalam kehidupan sehari-hari yang merupakan upaya untuk mencegah rusaknya lingkungan alam di sekitarnya, serta berusaha untuk memperbaiki segala kerusakan alam yang sudah terjadi, (2) pendidikan karakter peduli lingkungan dapat diimplementasikan di sekolah melalui pengintegrasian dalam mata pelajaran serta melalui program pengembangan diri.
\end{abstract}

Cara Mengutip

Purwanti, D. (2017). Pendidikan Karakter Peduli Lingkungan dan Implementasinya. DWIJACENDEKIA Jurnal Riset Pedagogik, 1(2), 14-20. 


\section{PENDAHULUAN}

Mata pelajaran di satuan pendidikan sejak tingkat dasar hingga menengah hampir semuanya sampai saat ini masih mengevaluasi aspek atau kompetensi kognitif, sedangkan evaluasi aspek afektif atau sikap dan aspek psikomotor belum dilaksanakan dengan sungguh-sungguh. Berkaitan dengan aspek afektif, pendidikan karakter sering terabaikan sehingga banyak keluhan, ketidakpuasan serta hujatan yang ditujukan pada sistem pendidikan kita.

Pemerintah melalui Kementerian Pendidikan Nasional Indonesia menanamkan pembentukan karakter melalui pendidikan sejak tahun 2010 termuat yang dalam Rencana Aksi Nasional Pendidikan Karakter. Pendidikan karakter yang ditetapkan kementrian pendidikan yang berjumlah 18 nilai atau karakter yang bersumber dari agama, Pancasila, budaya, dan tujuan pendidikan nasional. Nilai atau karakter tersebut adalah religius, jujur, toleransi, disiplin, kerja keras, kreatif, mandiri, demokratis, rasa ingin tahu, semangat kebangsaan, cinta tanah air, menghargai prestasi, bersahabat komunikatif, cinta damai, gemar membaca, peduli lingkungan, peduli sosial, dan tanggung jawab.

Namun lagi-lagi pendidikan karakter yang telah ditetapkan oleh pemerintah seolah-olah hanya menjadi slogan semata tidak dilaksanakan detail satu persatu. Karakter peduli lingkungan juga hanya menjadi pelengkap dalam catatan rencana mengajar guru, padahal karakter ini sangat diperlukan untuk menjaga keasrian lingkungan. Pendidikan karakter peduli lingkungan tidak terkelola dengan baik, padahal karakter peduli lingkungan memiliki manfaat yang cukup besar.

Pemerintah kembali mengeluarkan peraturan presiden nomor 87 tahun 2017 tentang penguatan pendidikan karakter. Kebijakan nasional pendidikan karakter dilakukan dalam rangka mewujudkan tujuan pendidikan nasional yaitu untuk berkembangnya potensi peserta didik agar menjadi manusia yang beriman dan bertakwa kepada Tuhan Yang Maha Esa, berakhlak mulia, sehat, berilmu, cakap, kreatif, mandiri, dan menjadi warga negara yang demokratis serta bertanggung jawab.

Berdasarkan kebutuhan tersebut maka dalam kajian ini akan dibahas tentang konsep pendidikan karakter peduli lingkungan dan implementasinya di sekolah. Fokus kajian ini berupa: (1) Definisi Pendidikan Karakter Peduli Lingkungan; (2) Tujuan Pendidikan Karakter Peduli Lingkungan; (3) Implementasi Pendidikan Karakter Peduli lingkungan di Sekolah.

\section{PEMBAHASAN}

\section{Definisi Pendidikan Karakter Peduli Lingkungan}

Pendidikan karakter sebagaimana kita ketahui, adalah pendidikan yang menanamkan kebiasaan (habituation) 
kepada manusia ataupun siswa tentang hal mana yang baik sehingga peserta didik menjadi paham (kognitif) mana yang benar dan salah, mampu merasakan (afektif) nilai yang baik, dan biasa melakukannya (psikomotor).

Ratna Megawangi (dalam Najib, 2016: 62) mengungkapkan bahwa pendidikan karakter merupakan suatu usaha untuk mendidik anak-anak agar dapat mengambil keputusan dengan bijak dan mempraktikannya dalam kehidupan sehari-hari sehingga mereka dapat memberikan kontribusi yang positif kepada lingkungannya.

Daryanto (2013: 64) mengartikan pendidikan karakter merupakan berbagai usaha yang dilakukan oleh para personil sekolah, bahkan yang dilakukan bersama-sama dengan orang tua dan anggota masyarakat untuk membantu anak-anak dan remaja agar menjadi atau memiliki sifat peduli, berpendirian, dan bertanggung jawab.

Berdasarkan berbagai pengertian di atas, dapat disimpulkan bahwa pendidikan karakter adalah semua usaha yang dilakukan oleh personil sekolah, orang tua dan masyarakat kepada anak-anak untuk mendidik, menanamkan, dan mengembangkan karakter luhur sehingga mereka dapat mengambil keputusan dengan bijak untuk mempraktikkan dalam kehidupannya dan memberikan kontribusi yang positif kepada lingkungannya.

Peduli lingkungan didefinisikan sebagai sikap dan tindakan yang selalu berupaya mencegah kerusakan pada lingkungan alam di sekitarnya dan mengembangkan upaya-upaya untuk memperbaiki kerusakan alam yang sudah terjadi. Dapat dikatakan karakter peduli lingkungan yaitu suatu sikap yang dimiliki oleh seseorang yang berupaya untuk memperbaiki dan mengelola lingkungan sekitar secara benar sehingga lingkungan dapat dinikmati secara terus menerus tanpa merusak keadaannya, serta menjaga dan melestarikan sehingga ada manfaat yang berkesinambungan.

Karakter peduli lingkungan merupakan karakter yang wajib diimplementasikan bagi sekolah di setiap jenjang pendidikan. Semua warga sekolah harus mempunyai sikap peduli terhadap lingkungan dengan cara meningkatkan kualitas lingkungan hidup, meningkatkan kesadaran warga sekolah tentang pentingnya peduli lingkungan serta mempunyai inisiatif untuk mencegah kerusakan lingkungan. Pendidikan karakter peduli lingkungan ditanamkan sejak dini kepada siswa sehingga dapat mengelola secara bijaksana sumber daya alam yang ada di sekitar, serta untuk menumbuhkan rasa tanggung jawab terhadap kepentingan generasi penerus yang akan datang. Ketika karakter peduli lingkungan sudah tumbuh menjadi mental yang kuat, maka akan mendasari perilaku seseorang dalam kehidupan seharihari.

Pendidikan karakter peduli lingkungan pada dasarnya membantu guru dalam penanaman karakter siswa tentang kepedulian mereka terhadap lingkungan. Pendidikan karakter peduli lingkungan dapat menjadi tolok ukur kepedulian serta kepekaan siswa kepada lingkungannya. Kepedulian dan kepekaan siswa terhadap 
lingkungan akan suasana belajar mengajar yang sehat dan nyaman. Lingkungan sekolah atau suasana belajar mengajar yang sehat dan nyaman dapat meningkatkan prestasi dan kreativitas siswa.

\section{Tujuan Pendidikan Karakter Pendidikan Lingkungan}

Najib (2016:71) mendeskripsikan tujuan pendidikan karakter antara lain:

a. Menciptakan lingkungan sekolah yang kondusif bagi peserta didik pada khususnya dan seluruh warga sekolah pada umumnya dalam menjalin interaksi edukasi yang sesuai dengan nilai-nilai kakater.

b. Membentuk peserta didik yang memiliki kecerdasan emosional dan kecerdasan spiritual (emotional and spiritual quotient/ESQ).

c. Menguatkan berbagai perilaku positif yang ditampilkan oleh peserta didik baik melalui kegiatan pembelajaran maupun pembiasaan di kelas dan sekolah.

d. Mengoreksi berbagai perilaku negative yang ditampilkan oleh peserta didik ketika berada di lingkungan sekolah maupun di lingkungan keluarga.

e. Memotivasi dan membiasaka peserta didik mewujudkan berbagai pengetahuan tentang kebaikan (knowing the good) dan kecintaannya akan kebaikan (loving the good) ke dalam berbagai perilaku positif di lingkungan sekolah dan lingkungan keluarga.

Marsanti (rakyatpos.com 17 Januari 2014), tujuan pendidikan karakter peduli lingkungan adalah: a. Mendorong kebiasaan dan perilaku peserta didik yang terpuji dan sejalan dengan pengelolaan lingkungan yang benar;

b. Meningkatkan kemampuan untuk menghindari sifat-sifat yang dapat merusak lingkungan;

c. Memupuk kepekaan peserta didik terhadap kondisi lingkungan sehingga dapat menghindari sifatsifat yang dapat merusak lingkungan;

d. Menanam jiwa peduli dan bertanggung jawab terhadap kelestarian lingkungan.

Akhir tujuannya adalah agar siswa menjadi duta lingkungan bagi sekolah, rumah, dan lingkungan sekitarnya serta menjadikan sikap atau karakter tersebut menjadi tabiatnya dalam kehidupan dimanapun dia berada. Karakter peduli lingkungan tidak hanya bersifat teoritis saja tetapi dituntut sebuah tindakan nyata yang membawa perubahan baik bagi kehidupan semua orang, Zulian (kompasiana.com 3 Mei 2016)

Dari berbagai uraian tentang tujuan pendidikan karakter peduli lingkungan, bahwa karakter peduli lingkungan bertujuan untuk mendorong kebiasaan mengelola lingkungan, menghindari sifat merusak lingkungan, memupuk kepekaan terhadap lingkungan, menanam jiwa peduli dan tanggungjawab terhadap lingkungan, serta siswa dapat menjadi contoh penyelamat lingkungan dalam kehidupan dimanapun berada.

3. Implementasi Pendidikan Karakter Peduli Lingkungan

Pendidikan karakter harus disampaikan kepada siswa, namun tidak menjadi pelajaran tersendiri. 
Pengintegrasian ke dalam mata pelajaran, pengembangan diri, dan budaya sekolah merupakan implementasi dari pendidikan karakter termasuk karakter peduli lingkungan. Karakter peduli lingkungan diintegrasikan ke dalam Kurikulum Tingkat Satuan Pendidikan (KTSP),Silabus dan Rencana Program Pembelajaran (RPP) yang sudah ada.

Implementasi pendidikan karakter yang dilakukan sekolah terlihat pada tabel (Aqib, 2017:22).

\begin{tabular}{|c|c|}
\hline \multicolumn{2}{|c|}{$\begin{array}{l}\text { IMPLEMENTASI PENDIDIKAN } \\
\text { KARAKTER DALAM KTSP }\end{array}$} \\
\hline $\begin{array}{l}\text { Integrasi } \\
\text { dalam mata } \\
\text { pelajaran } \\
\text { yang ada }\end{array}$ & $\begin{array}{l}\text { Mengembangkan } \\
\text { silabus dan RPP } \\
\text { pada kompetensi } \\
\text { yang telah ada } \\
\text { sesuai dengan nilai } \\
\text { yang akan } \\
\text { diterapkan }\end{array}$ \\
\hline $\begin{array}{l}\text { Mata } \\
\text { pelajaran } \\
\text { dalam mulok }\end{array}$ & $\begin{array}{l}\text { a. Ditetapkan oleh } \\
\text { sekolah/daerah } \\
\text { b. Kompetensi } \\
\text { dikembangkan } \\
\text { oleh } \\
\text { sekolah/daerah }\end{array}$ \\
\hline $\begin{array}{l}\text { Kegiatan } \\
\text { Pengembang } \\
\text { an Diri }\end{array}$ & $\begin{array}{l}\text { a. Pembudayaan } \\
\text { dan Pembiasaan } \\
\text { 1) Pengkondisia } \\
n \\
\text { 2) Kegiatan rutin } \\
\text { 3) Kegiatan } \\
\text { spontanitas } \\
\text { 4) Keteladanan } \\
\text { 5) Kegiatan } \\
\text { terprogram } \\
\text { b. Ekstrakurikuler } \\
\text { Pramuka; PMR; } \\
\text { Kantin Kejujuran; } \\
\text { UKS; KIR; } \\
\text { Olahraga; Seni; } \\
\text { OSIS. }\end{array}$ \\
\hline
\end{tabular}

\begin{tabular}{|l|l|}
\hline & $\begin{array}{l}\text { C. Bimbingan } \\
\text { Konseling } \\
\text { Pemberian } \\
\text { layanan bagi } \\
\text { anak yang } \\
\text { mengalami } \\
\text { masalah. }\end{array}$ \\
\hline
\end{tabular}

Dari tabel tersebut dapat dikatakan bahwa karakter peduli lingkungan diimplementasikan melalui tiga cara yaitu terintegrasi dalam mata pelajaran dengan menyesuaikan kompetensi yang ada, menjadi salah satu muatan lokal di sekolah yang tentunya telah disepakati oleh sekolah, serta melalui kegiatan pengembangan diri yang terdiri dari pembudayaan dan pembiasaan, ekstrakurikuler, dan bimbingan konseling.

Implementasi pendidikan karakter menurut Daryanto (2013:74) dilaksanakan melalui (a) kegiatan pembelajaran: menggunakan pendekatan pembelajaran aktif; (b) pengembangan budaya sekolah dan pusat kegiatan belajar, yang dilakukan melalui kegiatan pengembangan diri diantaranya kegiatan rutin, kegiatan spontan, keteladanan, pengkondisian, kegiatan ko kurikuler dan ekstrakurikuler serta kegiatan keseharian di rumah dan di masyarakat.

Menurut pendapat penulis bahwa untuk mengimplementasikan nilai karakter peduli lingkungan diiintegrasikan pada setiap mata pelajaran melalui standar kompetensi yang ada, pembelajaran yang aktif dengan menanamkan karakter peduli lingkungan pada kegiatan belajar mengajar pada setiap pokok bahasan, melalui kegiatan pengembangan diri yang telah ditentukan oleh sekolah 
serta melalui budaya sekolah yang sehingga menjadi ciri khas.

diunggulkan oleh sekolah tersebut

\section{SIMPULAN}

Pendidikan karakter peduli lingkungan merupakan salah satu dari delapan belas karakter yang ditetapkan oleh Pusat Kurikulum Kementerian Pendidikan Nasional. Pendidikan karakter peduli lingkungan yaitu suatu sikap yang dimiliki seseorang untuk memperbaiki dan mengelola lingkungan secara benar dan bermanfaat sehingga dapat dinikmati secara terus menerus tanpa merusak keadaannya, turut menjaga dan melestarikan sehingga ada manfaat yang berkesinambungan.

Tujuan pendidikan karakter peduli lingkungan adalah mendorong kebiasaan kepada siswa untuk mengelola lingkungan, menghindari sifat merusak lingkungan, memupuk kepekaan terhadap lingkungan, menanam jiwa peduli dan tanggungjawab terhadap lingkungan, serta siswa dapat menjadi contoh penyelamat lingkungan dalam kehidupan dimanapun berada.

Implementasi Pendidikan Karakter Peduli Lingkungan teridiri dari: diiintegrasikan pada setiap mata pelajaran melalui standar kompetensi yang ada, pembelajaran yang aktif dengan menanamkan karakter peduli lingkungan pada kegiatan belajar mengajar pada setiap pokok bahasan, melalui kegiatan pengembangan diri yang telah ditentukan oleh sekolah serta melalui budaya sekolah yang diunggulkan oleh sekolah tersebut sehingga menjadi ciri khas.

\section{DAFTAR PUSTAKA}

Aqib Zainal, \& Amrullah A. (2017).

Pedoman Pendidikan Budaya dan Karakter Bangsa. Yogyakarta.Gava Media

Daryanto \& Darmiatun. (2013). Implementasi Pendidikan Karakter di Sekolah. Yogyakarta: Gava Media

Jamal Ma'mur Asmani. (2012). Buku Panduan Internalisasi Pendidikan Karakter di Sekolah. Yogyakarta: Diva Press.

Kemdiknas. (2010). Pendidikan Budaya dan Karakter Bangsa
Pedoman Sekolah. Jakarta: Kementerian Pendidikan Nasional

Khan Yahya. (2010). Pendidikan Karakter Berbasis Potensi Diri: Mendongkrak Kualitas Pendidikan: Yogyakarta. Pelangi Publishing

Lickona. (2015). Mendidik Untuk Membentuk Karakter: Bagaimana Sekolah dapat Mengajarkan Sikap Hormat dan Tanggung Jawab: Jakarta. Bumi Aksara 
Najib M, dkk (2016). Manajemen Strategik Pendidikan Karakter Bagi Anak Usia Dini. Yogyakarta. Gava Media

Pupuh Fathurrohman dkk. (2013). Pengembangan Pendidikan Karakter. Bandung: Refika Aditama

Wibowo Agus. (2012). Pendidikan Karakter: Strategi Membangun Karakter Bangsa Berperadaban. Yogyakarta: Pustaka Pelajar.
Wibowo Agus. (2015). Pendidikan Karakter Berbasis Kearifan Lokal di Sekolah (Konsep, Strategi dan Implementasi). Yogyakarta; Pustaka Pelajar.

http://www.rakyatpos.com/membang un-karakter-peduli-lingkungan-disekolah-upaya-penyelematanlingkungan-hidup.html

http://www.kompasiana.com/mespin /pendidikan-karakter-cintalingkungan-sebagai-upayamenyelamatkanlingkungan_5727faf5f6 